\title{
Neurological Model
}

National Cancer Institute

\section{Source}

National Cancer Institute. Neurological Model. NCI Thesaurus. Code C16868.

A model that simulates behavior or neurological activity using computers and/or mathematical representation. 